\title{
ST Segment Elevation Myocardial Infarction (STEMI) in the Elder- ly over 75 Years: Retrospective Study in a General Hospital
}

\author{
Abrar-Ahmad ZULFIQAR MD, MSc ${ }^{1^{*}}$ and Marphy KERIF MD \\ ${ }^{1}$ Department of Internal Medicine-Geriatrics-Therapeutics, University Hospital of Rouen, France \\ ${ }^{2}$ Department of Emergency Unit, Hospital of Troyes, France
}

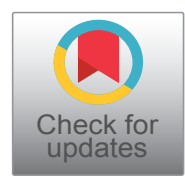

*Corresponding author: Abrar-Ahmad ZULFIQAR MD, MSc, Department of Internal Medicine Geriatrics-Therapeutics, University Hospital of Rouen, 76000 Rouen, France, Tel: 0627102493, Fax: 02-35-63-64-64

\begin{abstract}
Data on ST elevation myocardial infarction in patients aged over 75 years remains sporadic. The prognosis for ST Segment Elevation Myocardial Infarction (STEMI) patients is bleak. Mortality at one year in patients aged over 80 years is very high. We describe a series of elderly patients over 75 years treated by emergency physicians in pre-admissions or in emergency wards presenting with acute ST elevation myocardial infarction, and we compare these data with a second group of patients aged below 75 years.
\end{abstract}

\section{Keywords}

ST elevation myocardial infarction, Elderly, Angiograms, Prognosis

Data on ST elevation myocardial infarction in patients aged over 75 years remains sporadic. We completed a retrospective study at the Centre Hospitalier de Troyes, including all patients aged over 75 years treated by emergency physicians in pre-admissions or in emergency wards presenting with acute ST elevation myocardial infarction between January 2015 and February 2016 inclusive. We also identified a second group of subjects, aged below 75 years, with the same number of members, in order to be able to perform a cross-analysis.

We retrieved details of 32 patients aged over 75 years, with a mean age of 84.56 years ( $75-100$ years), of which 22 were women. The mean Charlson comorbidity score is estimated at $3.44(1-8)$ and the mean Grace score is estimated at 216 (168-345). Reperfusion was performed by way of an angiogram in $46.75 \%$ of cases; No patient in this group was subject to thrombolysis.
The mean time before performance of the initial angiogram is estimated at 5,149 minutes (or over 85 hours); Approximately $21.9 \%$ of patients were treated by way of insertion of a stent. One half of angiograms were not accompanied by the insertion of stents. Mortality during hospitalization occurred in ten cases and, in total, 12 patients passed away within six months. Thirty-one patients aged below 74 years, with a mean age of 55.06 years (25-74 years) were included in a study over a shorter period, namely three months, with the majority being men (27 subjects). Angiograms were performed in $96.77 \%$ cases, whereas thrombolysis was performed in the cases of only two patients. We did not record any mortality during hospitalization, nor at an interval of one month or three months. There are more female subjects among patients aged over 75 years and more male subjects among patients aged below 75 years $(p<0.0001)$. Subjects aged over 75 years were more likely to have consulted their treating physician prior to attending the emergency ward $(p=0.002)$. The Charlson score is more significant in subjects aged over 75 years $(p<0.0001)$; The same applies for the Grace score $(p<0.0001)$. Subjects aged over 75 years were provided with less access to angiograms than subjects aged below 75 years and were less likely to benefit from a stent insertion $(p<0.0001)$. Age $>=75$ years increases the risk of mortality during hospitalization $(p=0.001)$, at one month $(p=0.001)$ and at six months $(p<0.0001)$.

The prognosis for ST Segment Elevation Myocardial Infarction (STEMI) patients is bleak. Mortality at one year in patients aged over 80 years is seven times higher than for patients aged below 70 years in the ASC 
II register [1]. In the GRACE register, age was highlighted as an independent factor correlated with the absence of reperfusion treatment during the acute phase, along with a history of surgical revascularization, diabetes, heart failure, and the absence of chest pain [2]. In the PLATO ELDERLY study, angiograms were deployed in 56.6\% of cases, with angioplasty a featuring in $73.2 \%$ [3]. A recent study on sudden cardiac arrest in elderly patients based on the ACOS register shows that mortality during hospitalization was recorded at a rate of $12.5 \%$ among the medical treatment group, compared to $6 \%$ among the group that benefited from an invasive treatment strategy [4]. In the FAST-MI register, $85.3 \%$ of patients aged below 65 years were treated via angioplasty or fibrinolysis in cases of STEMI, compared to only $53.6 \%$ of subjects aged over 85 [5]. According to Kuch, angioplasty is the single predictive factor for survival at 18 months [6]. Coronary angioplasty in subjects aged over 85 years is thus technically feasible with a satisfactory success rate and acceptable rates of morbidity and mortality, given the severity of the coronary condition and the associated comorbidity [7]. Mortality is the criterion used in studies to judge the effectiveness of coronary angioplasty in octogenarian patients, but it is also important to assess quality of life as suggested by Shah, et al. demonstrating that angioplasty performed in subjects aged over 75 suffering from STEMI is an independent predictive factor for an improvement in long-term survival, and also demonstrating that their quality of life is comparable with that of a similarly aged, non-institutionalized control population [8]. STEMI in elderly subjects remains a current topic, both in terms of therapy and prognosis.

\section{Conflict of Interest}

None.

\section{Acknowledgment}

None.

\section{Conflict of Interest}

None.

\section{References}

1. Mandelzweig L, Battler A, Boyko V, Bueno H, Danchin N, et al. (2006) The second euro heart survey on acute coronary syndromes: Characteristics, treatment, and outcome of patients with ACS in Europe and the mediterranean basin in 2004. Eur Heart J 27: 2285-2293.

2. Devlin G, Gore JM, Elliott J, Wijesinghe N, Eagle KA, et al. (2008) Management and 6-month outcomes in elderly and very elderly patients with high-risk non-ST-elevation acute coronary syndromes: The global registry of acute coronary events. Eur Heart J 29: 1275-1282.

3. Husted S, James S, Becker RC, Horrow J, Katus H, et al. (2012) Ticagrelor versus clopidogrel in elderly patients with acute coronary syndromes: A substudy from the prospective randomized platelet inhibition and patient outcomes (Plato) trial. Circ Cardiovasc Qual Outcomes 5: 680-688.

4. Bauer $\mathrm{T}$, Koeth $\mathrm{O}$, Jünger $\mathrm{C}$, Heer $\mathrm{T}$, Wienbergen $\mathrm{H}$, et al. (2007) Effect of an invasive strategy on in-hospital outcome in elderly patients with non-ST-elevation myocardial infarction. Eur Heart J 28: 2873-2878.

5. Puymirat E, Aissaoui N, Simon T, Bataille V, Drouet E, et al. (2013) Acute myocardial infarction in the elderly. The fastmi registry. Presse Med 42: 1432-1441.

6. Kuch B, Wende R, Barac M, von Scheidt W, Kling B, et al. (2011) Prognosis and outcomes of elderly (75-84 years) patients with acute myocardial infarction 1-2 years after the event: AMI-elderly study of the MONICA/KORA myocardial infarction registry. Int J Cardiol 149: 205-210.

7. Deman AL, Schiano $P$, Chenilleau MC, Barbou F, Martin $A C$, et al. (2010) Les patients très âgés sont-ils de bons candidats à l'angioplastie coronaire? Une étude rétrospective monocentrique. Ann Cardiol Angeiol 59: 278284.

8. Shah P, Najafi AH, Panza JA, Cooper HA (2009) Outcomes and quality of life in patients $>$ or $=85$ years of age with STelevation myocardial infarction. Am J Cardiol 103: 170-174.

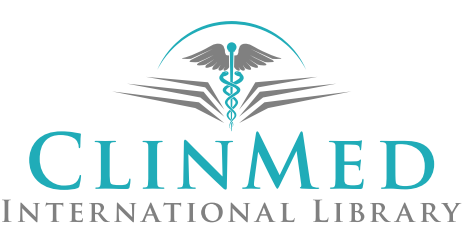

